\title{
A perspectiva biomédica dos transtornos alimentares e seus desdobramentos em atendimentos psicológicos'
}

\author{
Raquel Lima Pedrosa* \\ Leônia Cavalcante Teixeira \\ Programa de Pós-graduação em Psicologia \\ Universidade de Fortaleza. Fortaleza, CE, Brasil
}

\begin{abstract}
Resumo: Este artigo tem como objetivo analisar os desdobramentos da perspectiva biomédica em atendimentos psicológicos em um serviço interdisciplinar de transtornos alimentares. A metodologia consistiu em uma pesquisa documental de prontuários dos pacientes atendidos no programa diagnosticados com transtorno alimentar e que estavam em atendimento no período de agosto de 2012 a janeiro de 2013. As categorias clínicas privilegiadas nesta análise foram transferência, sintomas e diagnóstico. Ao todo foram 17 prontuários, todos de pacientes do sexo feminino, com idades entre 14 e 61 anos. Identificamos além da prevalência do discurso biomédico nos relatos de sessões, questões subjetivas presentes no discurso do paciente, mas pouco elaboradas nos prontuários, como as relações familiares, questões da oralidade, puberdade e da feminilidade. A partir da teoria psicanalítica de Freud e Lacan, discutimos tais questões, ressaltando a importância para a compreensão e acompanhamento de pacientes com transtornos alimentares.
\end{abstract}

Palavras-chave: biomedicina, psicanálise, clínica interdisciplinar, transtorno alimentar.

\section{Introdução}

Os transtornos alimentares são considerados, pela biomedicina, como um distúrbio no comportamento alimentar e têm como principal característica uma séria perturbação da imagem corporal e o temor exagerado de engordar. Entre os principais transtornos estão: a anorexia - que é caracterizada por uma recusa a manter, em um nível saudável, o peso corporal - e a bulimia, caracterizada por uma ingestão descontrolada de muitos alimentos, seguida de comportamentos de expulsão, como vômitos, jejuns e exercício físicos excessivos. (DSM-IV e CID-10).

Hoje, é possível observar o aumento expressivo do número de pacientes com transtornos alimentares na clínica e o alto índice de mortalidade. Muitos autores que trabalham com os transtornos alimentares justificam o aumento da incidência desses casos devido ao mal-estar, referente às exigências corporais contemporâneas. $\mathrm{O}$ comer se reflete diretamente no corpo, logo, apresenta-se, também, como ideal de saúde e boa aparência. Priore (2006) e Bosi e Andrade (2004) chamam a atenção para a valorização da magreza como sinônimo de sucesso e poder.

Neste artigo, partimos do pressuposto de que esses fatores não seriam meramente causais, mas gatilhos de uma dinâmica pré-existente. Sabe-se da influência negativa que a imposição do padrão estético, valorizado socialmente,

1 Agradecimento: Fundação Cearense de Apoio ao Desenvolvimento Científico e Tecnológico.

* Autora correspondente: raquel.lpedrosa@gmail.com, raquel.lpedrosa@ hotmail.com pode exercer no desenvolvimento do sujeito, mas é importante ressaltar que apenas essa perspectiva não abrange todo o problema, pois não se trata apenas do corpo biológico. Trata-se de um corpo atravessado pela linguagem.

De acordo com Sousa (1991), no contexto clínico, lidamos com um corpo anatômico e um corpo vivido. $\mathrm{O}$ primeiro nós descobrimos na doença, por exemplo. Só lembramos que temos órgãos após as complicações clínicas dos transtornos alimentares, como amenorreia e problemas cardíacos, entre outros. O corpo vivido seria o corpo simbólico, que nos remete a subjetividade; neste último, "o sintoma é a fala do corpo manifesta no sofrimento" (Sousa, 1991, p. 35). Ou seja, os sintomas da oralidade denunciariam, no corpo, um sofrimento psíquico.

A partir desta perspectiva, justificamos a utilização do termo "transtorno oral" porque, além de ser um vocábulo já utilizado por autores da psicanálise, representa a abrangência deste campo. Consideramos o campo dos transtornos orais como um espaço de estudos privilegiado, que pode decorrer de múltiplas perspectivas de reflexão, centradas tanto na biomedicina como na psicanálise, na medida em que se trata de um problema psíquico que se manifesta eminentemente no corpo e tem como consequências sintomas físicos e clínicos que são privilegiadamente dirigidos ao médico. Do mesmo modo, também o observamos como um campo polêmico de trabalho, uma vez que estamos diante de divergências teóricas, conceituais e terapêuticas.

A biomedicina é composta pelas ciências que se utilizam da morfologia e da fisiologia para o diagnóstico, intervenções e tratamentos. $\mathrm{O}$ corpo dividido, em uma visão fatorialista, é referência central para a conduta biomédica. 
Justificamos a utilização do termo biomedicina por considerarmos que reflete mais adequadamente a vinculação da racionalidade médica com o conhecimento produzido por disciplinas científicas do campo da Biologia. Devido ao envolvimento de uma gama de profissionais no estudo e tratamento dos transtornos alimentares, o termo biomedicina auxilia na concisão da elaboração deste artigo (Camargo Jr., 1997).

O discurso biomédico é o discurso da ciência, prende-se ao corpo e se baseia no olhar e na descrição para a constituição de seu objeto de estudo. Sua explicação, geralmente, é concebida como causal, através da ajuda da intuição, somada à experiência de outros casos. $\mathrm{O}$ trabalho consiste em descartar as particularidades do sujeito para enquadrá-lo nos parâmetros nosológicos. Nesse contexto, a subjetividade do indivíduo interfere na objetividade cientifica e terapêutica pretendida.

Oposta à biomedicina, a prática clínica psicanalítica se centra no sujeito do inconsciente e suas vicissitudes, sujeito do inconsciente, atravessado pela linguagem, marcado pelo encontro com o Outro. Freud (1913/1996a, 1912/1996b) propõe a psicanálise como uma ciência do sujeito apreendido pela escuta, que seria a ferramenta principal para a construção de hipóteses e interpretações. Cada caso é único, não podendo ser limitado a diagnósticos prontos, mas isso não significa que a singularidade exclua a possibilidade de generalização teórica e o consequente estabelecimento de diretrizes terapêuticas. O caso-a-caso se constitui pela relação recíproca entre o singular do caso e o geral da teoria, sendo polos que se constroem reciprocamente, atualizados pela práxis clínica.

Para a clínica psicanalítica, a ênfase recai sobre a subjetividade, e os sintomas são percebidos como estratégia do sujeito, uma vez que nos dão indícios da forma como o sujeito se relaciona com o Outro, evidenciando angústias primitivas relacionadas aos primeiros momentos de sua constituição. Eles representam manifestações de um intenso sofrimento psíquico, um descompasso na relação entre mãe e bebê. O referencial fundamental que rege a prática é o inconsciente que, para Freud (1913/1996a, 1912/1996b), constitui a verdade do sujeito e do seu desejo.

Para o campo de saúde mental, essas múltiplas perspectivas, centradas em campos tão distintos, como a biomedicina e a psicanálise, configuram-se como um desafio para o profissional, para a instituição e para o indivíduo que sofre. O Programa interdisciplinar de Nutrição de Transtornos alimentares e Obesidade (Pronutra) é um programa da Universidade de Fortaleza (Unifor) que se propõe a responder estes desafios da multidisciplinaridade no campo da saúde mental e dos transtornos alimentares.

O Pronutra é um programa de extensão, vinculado ao curso de nutrição, mas também é composto por profissionais da medicina e da psicologia. É realizado a partir de atendimentos clínicos individuais aos pacientes com transtornos alimentares e de reuniões semanais entre os profissionais envolvidos no projeto visando à discussão sobre estratégias terapêuticas dos casos atendidos. O paciente se vincula a dois setores diferentes, mas que estão interligados pelo objetivo interdisciplinar do programa de extensão: ao setor de nutrição, no qual são realizados os atendimentos médico e nutricional, e ao Serviço de Psicologia Aplicada (SPA), no qual são realizados os acompanhamentos psicológicos.

Funciona no Núcleo de Atendimento Médico Integrado (Nami), em Fortaleza, Ceará, desde 2005 e pertence à rede básica de saúde mental do município. Por isso, apesar de fazer parte de uma clínica-escola, acolhendo estagiários de diversas áreas, o serviço não se resume a essa função, possuindo um lugar de destaque no cenário do Estado do Ceará no campo da saúde mental, daí termos optado, nesta investigação, estudar o Pronutra a partir da perspectiva de uma instituição interdisciplinar que é regida pelo exercício das diretrizes da atenção básica à saúde. Mesmo quando os atendimentos são realizados por estagiários, os professores/supervisores e a equipe multidisciplinar do Pronutra acompanham os encaminhamentos.

Apesar da recomendação de um trabalho em equipe, ainda é comum observar, nos serviços de saúde, a hegemonia do modelo biomédico na decisão do diagnóstico e tratamento que, por sua vez, são estabelecidos a partir de uma coleção de sintomas, que são considerados alheios ao indivíduo. Essa realidade é ressaltada na conduta do tratamento, nos usos de medicação, na visão da doença como um distúrbio a ser curado e no corpo, reduzido a um organismo.

Ao participarmos das reuniões do Pronutra, deparamos com a realidade da hegemonia biomédica, inclusive no discurso dos profissionais de psicologia, independentemente da abordagem terapêutica com que trabalhavam. A análise documental, realizada nos prontuários de psicologia, apontou que o mesmo acontece nos relatos das sessões e nas análises dos casos, que deveriam se caracterizar como um rico espaço de investigação teórica, diálogo e construção do caso, mas que se limitam à descrição de um conjunto objetivo de sintomas e comportamentos.

Vale ressaltar que o registro das sessões tem caráter obrigatório, de acordo com a lei, pela resolução do Conselho Federal de Psicologia (CFP) 001/2009, e deve conter o apontamento da evolução do trabalho, de modo a permitir o conhecimento do mesmo, bem como os procedimentos adotados e o registro de encaminhamentos ou encerramentos. Também é destacada a importância de serem registradas apenas as informações necessárias ao cumprimento dos objetivos de trabalho, mas isso não implica a exclusão de apontamentos, reflexões clínicas e teóricas, fundamentais à condução do caso.

Zanetti e Kupfer (2006) defendem a importância do relato de caso na instituição, como um instrumento de trabalho e pesquisa, tanto quanto os demais dispositivos institucionais, como as reuniões clínicas, mas ressaltam a necessidade de implicação daquele que se propôs a produzi-lo, na tentativa de apresentar um enigma do caso, muitas vezes perdido entre as teorias já estabelecidas sobre ele, e construir os significantes que o compõem. Essa interrogação é fundamental para a pesquisa em psicanálise e é 
por essa perspectiva que analisamos o material produzido pelos que ocupam o lugar de terapeutas.

Diante da problemática exposta da hegemonia do modelo biomédico, este artigo teve como objetivo analisar os desdobramentos dessa perspectiva em atendimentos psicológicos em um serviço interdisciplinar de transtornos alimentares. Na discussão ressaltamos a falta de elementos subjetivos nas conduções dos casos e a importância de questões trazidas pela teoria psicanalítica para a compreensão desse contexto, como relações familiares, questões da oralidade, puberdade e feminilidade.

A seguir, realizaremos uma síntese dos 17 prontuários de psicologia analisados de pacientes diagnosticados com transtorno alimentar atendidos no Pronutra entre agosto de 2012 e janeiro de 2013, evidenciando o estilo de elaboração textual, os principais assuntos abordados e considerando as categorias que se destacaram na análise do conteúdo durante as leituras dos relatos dos prontuários: transferência, diagnóstico e sintomas.

\section{Sínteses dos prontuários de psicologia em um programa interdisciplinar de transtornos alimentares: apontamentos sobre a ressonância da leitura biomédica}

Com a escrita permeada pelo discurso biomédico apontaremos, a seguir, as principais características encontradas nos prontuários de psicologia. É importante lembrar que o estilo de narrativa e os assuntos abordados variaram durante o mesmo prontuário, uma vez que, em alguns casos, houve troca de terapeutas ao longo do acompanhamento psicológico dos pacientes. Outro dado importante é que, dos 17 prontuários analisados, dois não tinham relatos clínicos da psicologia e um não tinha o relato de um dos terapeutas.

Nos prontuários foram encontrados dois tipos de narrativas, as resumidas e pontuais e as descritivas. Ambas se caracterizam de modo objetivo, tal como a escrita biomédica: "Relatou que está namorando. Ficou sem almoçar". A ênfase recai sobre fatos cotidianos, sentimentos e estados de humor. Em todos são descritas as narrativas dos pacientes, alguns alternando em terceira pessoa e recortes da fala do paciente. Os relatos não verbais também ganham destaque, enfatizando as características comportamentais. Em um prontuário a terapeuta descreve como a paciente "se olha no espelho, mexe na bolsa e olha para os lados".

Entre os assuntos relatados pelos pacientes, destacam-se: as relações parentais; os sintomas e os diagnósticos biomédicos; a puberdade; o corpo (físico); o peso (relacionado a números e à aparência de gorda ou magra); a desmotivação ou a dependência do programa e a questão do olhar e ser olhado; o suicídio e a automutilação. Os diversos temas são abordados sem questionamentos e aprofundamentos, o que nos deixa uma lacuna se não foram efetivamente realizados ou se apenas houve ausência de registro, remetendo-nos à problematização da regularidade, quanto à atualização desses documentos, e da orientação ética. De todo modo, vale ressaltar que os relatos se assemelham à triagem e ao relato biomédico.
No relato sobre a clínica são retratadas as atividades comportamentais realizadas, como o diário alimentar, desenhos e colagem. Apenas em um prontuário, a terapeuta cita a importância do silêncio no processo terapêutico, denominando "tempo terapêutico" o silêncio da paciente. Em outro, somos remetidos às dificuldades encontradas pela resistência da paciente: "a todo momento parece que está jogando com a terapeuta, mostrando abertamente seu desinteresse por si e pelo tratamento"; "hoje disse que sua resistência comigo ainda existe".

Dois prontuários nos chamaram a atenção porque trazem a reflexão quanto à conduta dos atendimentos. A primeira terapeuta implica a equipe a incentivar a paciente a buscar soluções efetivas para seus problemas (familiares, financeiros, de saúde etc.), uma vez que a paciente as elabora, mas não faz nada a respeito. A segunda terapeuta reflete os avanços e retrocessos, ao longo do processo terapêutico. Sobre estes, a mesma faz referência à "melhora da relação", entre ela e a paciente, e o retrocesso, refere-se "às recaídas" nos sintomas da compulsão alimentar.

Observamos que nesses dois prontuários, apesar de serem questões importantes para clínica, o discurso biomédico ainda está embutido nas reflexões realizadas. No primeiro, no momento em que a equipe é convidada a incentivar a paciente a buscar soluções, já que não consegue resolver seus problemas, é possível compreendê-las como alheias à paciente, algo que lhe é exterior, sem envolvê-la em seus impasses, tal como as doenças são interpretadas pela biomedicina. Elas acometeriam o indivíduo sem estar relacionadas às questões subjetivas. No segundo, os sintomas da compulsão alimentar são encarados como um retrocesso, em relação ao processo terapêutico. Ele nos remete à questão da cura, que é o objetivo principal do discurso biomédico, e na lógica do sintoma como um transtorno, um déficit.

Em outros dois prontuários fica mais evidente a ressonância da leitura biomédica na descrição dos sintomas. No primeiro, além do transtorno alimentar, a paciente se encontrava debilitada, devido a um sangramento intenso. A maior parte do relato da terapeuta trouxe o estado geral, físico e de humor, da paciente em decorrência desse sangramento. No segundo, a paciente se queixa de uma dor de cabeça que sempre aparece nos dias de atendimento da terapeuta. A ênfase deste prontuário recai sobre o desconforto físico, sem reflexão subjetiva sobre as possíveis relações entre a dor e o atendimento.

O diagnóstico também é permeado pela leitura biomédica. Além dos transtornos alimentares, é comum observar a descrição de outros, como: o Transtorno Obsessivo Compulsivo (TOC), a depressão, o alcoolismo e o transtorno de ansiedade. A ênfase é dada aos comportamentos repetitivos e compensatórios, mesmo quando estes são vinculados a sentimentos pelas próprias pacientes, como a um mal-estar, a raiva e preocupação.

Ainda sobre o diagnóstico, ressaltamos um prontuário em que o sintoma da paciente é denominado de "TOC grave". Este, por sua vez, foi subdividido de acordo com seu comportamento, o "TOC da sexualidade", que se 
caracterizou pela procura da paciente por um namorado para transar, e o "TOC do rosto", quando a paciente passava, excessivamente, cremes para espinhas, a ponto de queimar o rosto, ou quando passou a se maquiar e se olhar no espelho com uma frequência maior.

Em relação às questões clínicas, o incômodo de uma paciente é retratado pela presença de estudantes, durante os atendimentos de nutrição e psiquiatria, a ponto de prejudicar suas respostas, na tentativa de sair daquela situação o mais rápido possível. Outro ponto do relato é a angústia, apresentada a cada troca de profissionais, por causa de sua dificuldade de adaptação: "adoece ao lidar com o novo". A permuta de profissionais é comum no serviço, mas em nenhum dos prontuários isso é relatado como uma questão importante, os vínculos estabelecidos não são considerados nos relatos de psicologia.

Há reclamações constantes sobre dependência ou desmotivação, seja por problemas na equipe ou por não verem os resultados esperados. Tais ocorrências perpassam não só aspectos de funcionamento institucional, como também questões transferenciais, fundamentais ao processo terapêutico.

Não há menção sobre as transferências; são citadas, no máximo, situações que sugerem a relação transferencial, sobre a importância da relação entre nutricionista e paciente, trazendo os efeitos positivos dessa relação ao processo terapêutico; ou quando a terapeuta recebe um presente da paciente, que afirmou ser a sua cara. Nesse caso, a terapeuta comenta que a situação foi conversada, mas sem detalhar.

Em outras situações, encontramos relações mais conturbadas, sobretudo com a nutricionista que, algumas vezes, é comparada às mães das respectivas pacientes: "Acha que há algo na forma de ela aconselhar que lembra sua mãe"; "receio de tomar carão da nutricionista".

Ao admitir os afetos, com a troca de profissionais, e as semelhanças entre as relações estabelecidas entre a nutricionista e a mãe, as pacientes dão pistas de que há algo além a ser considerado nessas relações, no processo terapêutico dos transtornos alimentares, como as questões primitivas, subjetivas das primeiras relações, e seus desdobramentos em sua constituição.

Diante da análise realizada, evidencia-se a ressonância da leitura biomédica nos prontuários de psicologia, na reprodução de práticas objetivas e conceitos, que enfatizam o corpo como organismo e a doença como um déficit, um transtorno. Porém, esses mesmos relatos denunciam, pelo menos, quatro pontos subjetivos que precisam ser considerados, mas que escapam dessa perspectiva: as relações familiares, a questão da oralidade, a puberdade e a feminilidade.

\section{Para além da leitura biomédica na terapêutica dos transtornos alimentares: o que escapa a essa perspectiva?}

Ao analisarmos a ressonância da leitura biomédica nos atendimentos de psicologia, deparamos com questões subjetivas importantes, relatadas pelos pacientes e descritas pelos profissionais. São ocorrências que se repetem nos casos e exigem atenção daqueles que se propõem a pesquisar e atender pacientes com transtornos orais. $\mathrm{Na}$ análise desses prontuários, identificamos pelo menos quatro pontos que serão detalhados a seguir: as relações familiares, a relação com a oralidade, questões pubertárias e da feminilidade.

\section{Das relações familiares}

Nos relatos, as questões familiares, sobretudo a relação mãe e filha e as ausências paternas, são constantes. Observamos relações de extremos com as mães que vão desde o desamparo completo a uma quase simbiose entre as duas. Em relação às figuras paternas, referem-se à ausência por morte, ausência da autoridade paterna, ou seja, vivem na mesma casa, mas não trocam afetos, ou ausência física, geralmente após separação dos pais.

O desamparo está presente na maioria dos prontuários. As relações instáveis e a falta de amor são reclamações constantes dessas pacientes: seus sintomas e seus desdobramentos parecem estar diretamente relacionados a esse fato, a exemplo do relato de um prontuário, que afirma que a hospitalização foi importante no sentido de receber a atenção dos amigos e familiares.

Em outro prontuário, o pai da paciente relata o total abandono da mãe - "Faltava zelo, botar no braço, botar pra dormir" - e acredita que os problemas de saúde da filha podem estar ligados à mágoa que a mãe a causou. No relato da paciente é claro quanto ao desamparo: se sentia um "bebê monstro", afirmando que "só queria ser amada". Em um dos relatos chama a atenção para o nível de desamparo da paciente, quando a mãe solicita à equipe que deixe a filha sem comer, pelo menos um dia durante a semana. Vale ressaltar que, nesse caso, a paciente relata que a mãe a rejeita quando emagrece em demasia, chamando-a de "morta".

Por outro lado, também encontramos situações de extremo apego à mãe, a ponto de prejudicar o tratamento das pacientes. Em um dos relatos é descrita a presença intensa da mãe no processo terapêutico da filha. Apesar de achar desnecessário o tratamento, a mãe costuma estar presente, entrando, inclusive, por conta própria no atendimento psicológico da filha. A paciente também colabora com a situação ao se recusar a entrar no atendimento sem a mãe. Os relatos trazem conflitos constantes entre as duas, seguidos de culpa por parte da filha e a realização dos desejos da mãe.

A relação extremada entre mãe e filha também é evidenciada em outro relato, a ponto de a paciente relatar que, muitas vezes, acredita fazer escolhas em função do desejo da mãe e que muitas vezes não se reconhece por isso. A mãe também é caracterizada por tirar a liberdade da filha, por não deixá-la dormir sozinha. De acordo com o relato, a paciente "não quer ser tratada como menininha", dando pistas do tipo de vínculo problemático estabelecido entre elas. 


\section{Das questões da oralidade}

A ingestão de alimentos e o vômito estão associados a sentimentos de angústia e raiva ou de prazer. A nomeação de sentimentos relacionados aos sintomas dos transtornos alimentares, por parte dos pacientes, dá-nos indícios das relações estabelecidas na oralidade, demonstrando que não são meros comportamentos.

A comida, nesses casos, parece não se limitar à função de saciar o indivíduo fisicamente, mas também, emocionalmente; ou de promover a fuga de sentimentos de desprazer: "a comida é minha amiga"; "comeu muito, só engolia, não dava tempo nem de pensar"; "A paciente alega que a comida é a única coisa que dá prazer e que come devido a problemas familiares"; "Associa a compulsão aos momentos em que se sente só ... afirma que o foco da vida tá na comida e se esconde nela".

Ressalta-se que tais questões não se limitam à comida, pois durante os relatos, é comum ler frases como: "Teve que engolir muita coisa nessa vida calada"; "Acha que foi tarde demais quando aprendeu a falar e não aguentar tudo calada"; "Engole a comida da mesma forma que engole certos sapos".

Essas passagens expõem que, mais do que comportamentos, os atos de engolir e vomitar evidenciam a instabilidade da organização oral das pacientes, que se utilizam da incorporação na tentativa de solucionar suas questões, tais como aquelas estabelecidas com a comida, com as drogas ou com o álcool.

\section{Das questões da puberdade e da feminilidade}

Muitos relatos apresentaram angústia diante da sexualidade feminina e da puberdade. A menstruação é vivida como uma tragédia, acompanhada de enxaqueca e estresse e, algumas vezes, associada ao ganho de peso e que, por isso, elas evitam comer nesse período.

A narrativa de um prontuário descreve a puberdade como "mudanças esquisitas", o que deixou a paciente "toda errada". A adolescência também é descrita como um período de conflitos, pois de acordo com o relato, a paciente "acha chato crescer". Destacamos o relato de um prontuário específico, no qual a paciente queimou o rosto com o uso excessivo de cremes para espinhas, sem orientação. E o que são as espinhas, senão sinais da puberdade?

A partir da leitura, é possível observar como os sinais do surgimento do corpo feminino adulto são difíceis de ser suportados por essas pacientes. Tal fato sugere a falta de um suporte subjetivo de seu crescimento, nos seus primeiros anos de vida, que, por sua vez, está ligado à relação parental e ao desenvolvimento psicossexual delas.

Evidencia-se a importância da subjetividade na compreensão dos casos de transtornos alimentares, mais especificamente, dos vínculos estabelecidos com o casal parental em idades precoces e o desenvolvimento psicossexual, sobretudo, com a fase oral. Todos esses são elementos defendidos pela psicanálise como pontos básicos a serem considerados quando tratamos de paciente com sintomas de transtornos alimentares, pois não são alheios ao paciente, mas, na verdade, dizem respeito a sua constituição psíquica.

\section{O sujeito e a desmesura na constituição psíquica}

Cicco (2010), Kalil (2010), Nazar (2013) e Jeammet (1999) defendem que a gênese dos transtornos alimentares estaria vinculada a uma questão deste corpo libidinal, ou seja, a um problema no investimento erógeno da mãe sobre o seu bebê, ainda na fase oral. Por isso são reconhecidos, no meio psicanalítico, como transtornos da oralidade e não como distúrbios alimentares. A dimensão pulsional do corpo retorna do exterior, sob a forma de uma imperfeição da imagem. Há uma estranheza, uma defasagem entre o corpo e a imagem. Revela-se uma dificuldade em metabolizar a dimensão real do corpo pulsional, gerando distorções e uma enorme angústia, além de atestar a fragilidade da constituição psíquica.

Mais do que o leite, o olhar e a voz materna são os primeiros alimentos imbricados na acolhida do bebê. Quando a mãe não consegue ofertar o amor, que acolhe e inscreve a criança na ordem simbólica e familiar, uma gama de problemas estruturais pode surgir, entre eles, a instauração de um transtorno oral.

Para Kalil (2010) e Gorgatti (2002), a figura materna apresentaria dificuldades em entender as necessidades da criança, desconhecendo os diferentes tipos de choro e atendendo todas as solicitações da criança como necessidade concreta de alimento. Isso pode produzir no sujeito uma dificuldade de reconhecer suas necessidades internas, gerando alienação do sujeito ao Outro. Esta situação pode ser respondida, por sua vez, pela recusa anoréxica ou pela incorporação das bulímicas e obesas.

Segundo Lacan (1958/1998a), a criança e o desejo do Outro se tornam sinônimos. Seria pelo fato de suprir apenas a necessidade, que sobraria pouco espaço para o desejo advir. Assim, o que os sujeitos com transtornos orais reclamam é o que lhes foi negado, o acesso ao desejo e a forma encontrada por eles para afirmar seu desejo é recusando ou incorporando a comida. Estes movimentos se caracterizariam por uma busca para reiterar a demanda.

Portanto, compreende-se a importância da função materna em atender às diversas solicitações da criança, inclusive suas demandas de amor, que acompanham e superam a necessidade de alimento. Ser alimentado também remete a receber amor. Seria nesse ponto que a mãe se apresentaria não só fisicamente, como também psiquicamente, funcionando como um meio de regular a excitação do bebê, garantindo proteção, mediação e libidinização. É a partir desse momento, quando os objetos viram signos de amor, que o objeto primário pode ser substituído por outros.

No início do desenvolvimento, a figura materna propicia o acesso da criança à realidade, oferecendo a ela seu 
corpo e seu arsenal simbólico como meio de integrá-la ao campo do representado. Esta rede representacional vai, aos poucos, se formando e permitindo que a descarga da pulsão se dê por meio de caminhos mais longos e complexos, diferente da satisfação imediata do começo de vida, quando não se admite espera, nem mediadores (Cicco, 2010).

Diante de sujeitos com transtornos orais, é possível observar que o Outro não conseguiu ser mediador da introjeção das suas características, nem ser um suporte adequado para a organização pulsional e narcísica do sujeito, o que dificulta superar seu estado de dependência primária. Como o sujeito não dispõe de contenções do fluxo de excitação, dirige-se ao mundo externo através de atos.

Ressalta-se que os atos passam a ser uma forma de lidar com as pulsões precariamente recalcadas e que, ao longo do tempo, tornam-se repetitivos, sem satisfação, uma atividade automática e mecânica. O sujeito fica envolvido em repetições mortíferas, sem vontade, totalmente alienado e impossibilitado de interromper essa trama. Esses atos, não ditos, repetidos sobre o próprio corpo, remetem-nos ao modo silencioso da pulsão de morte.

Além da dificuldade do reconhecimento das necessidades da criança, Jeammet (1999) afirma que os transtornos da oralidade podem revelar, ainda, uma dinâmica específica das relações e dos investimentos no interior dos quais aconteceu uma má diferenciação entre sujeito/objeto. Observamos resultados aparentemente opostos quanto às relações estabelecidas, uma do tipo passional e outra do tipo evasiva e de retirada de investimentos, mas ambas provenientes do mesmo tipo de relação de objeto. Em outras palavras, Jeammet (1999) explica:

A relação com a alimentação é, desta forma, um protótipo do conjunto das relações que são feitas de uma luta ativa contra um desejo de se apropriar daquilo que lhes falta, um desejo de se preencher sem restrição, desejo contra o qual as anoréxicas lutam pela conduta oposta de privação daquilo que, com efeito, têm mais vontade. (p. 37)

Assim como a relação com a comida, o sujeito com transtorno oral vivencia angústias relacionadas ao encontro com o Outro. Ou se encontra muito próximo do Outro ao ponto de confundir-se com ele, ou se afasta excessivamente, colocando em risco o próprio sentido de si. O caráter desse momento é ambíguo: por um lado, sente a angústia de separação, por outro, da invasão, evidenciando a dificuldade de separação/diferenciação.

Ao passo que cabe à mãe atender às necessidades do bebê, investindo-o libidinalmente para assegurar a constituição dos seus processos de simbolização, também cabe a ela manter uma distância adequada que possibilite proteger o bebê de sua presença excessiva ou de sua ausência intolerável. Assim, nota-se a necessidade de que a mãe se retire temporariamente desse vínculo na tentativa de encontrar seu desejo em outro lugar. É este jogo de ausências e presenças que parece moldar o sujeito e suas demandas.
A constituição do sujeito depende estreitamente do que ele viveu na relação mãe-bebê no período pré-edípico e da forma como ele conseguiu tomar o seu lugar junto ao pai, posteriormente. Quando não há lugar para a ausência materna, há indicativos de uma dificuldade da mãe em investir no parceiro, em sua potência fálica, o que, por sua vez, pode resultar em um investimento no bebê como substituto fálico. Os investimentos narcísicos entre mãe e bebê impedem o reconhecimento do outro, a relação parental não é introjetada satisfatoriamente, podendo ocorrer uma "fusão" entre mãe e filho, uma vez que este passará a ser identificado como partes faltantes da mãe (Farias \& Cardoso, 2010).

É a ausência da mãe que possibilitará a separação entre ela e o bebê e o encontro com o terceiro, o pai, representante da potência fálica. Além disso, para que ocorra a diferenciação entre sujeito e objeto, é necessário que o primeiro experiencie a possibilidade de estar só, mesmo diante da relação com a mãe, ante o casal parental e sua sexualidade. Em outras palavras, deve existir a possibilidade do sujeito manter a relação necessária a sua constituição, mas, ao mesmo tempo, suficiente distante de seu objeto.

Entre os efeitos desse contexto, da mãe entre extremos, está a precariedade nas fronteiras que separam o eu e o Outro, ou como Miranda (2010b) denomina, um "corpo sem pele psíquica", incapaz de destacar sua singularidade. "Tudo se passa como se o corpo próprio não exercesse uma de suas funções, que é colocar os limites entre dentro e fora, exercendo assim o papel de fronteira entre o eu e o Outro" (Fernandes, 2010, p. 40).

Os sintomas orais viriam, assim, na tentativa de fazer as bordas do corpo, ou como Freire e Andrada (2012) denominam, de tocar a "pele psíquica". O encher-se e o esvaziar-se das bulímicas e o controle do peso corporal das anoréxicas se caracterizam como uma amostra física da busca pelo limite corporal. As noções de espaço, interno e externo, são deficitárias, inclusive da imagem de si mesmo internalizada.

Nesse contexto da diferenciação, é a introjeção que substitui a presença da mãe e que assegura ao bebê a possibilidade de lidar com sua ausência concreta, garantindo um apaziguamento diante das dificuldades no decorrer da vida. Isto significa que pela introjeção, o bebê vai criando, em seu mundo psíquico, uma representação.

É através da introjeção que há uma ampliação do ego, garantindo ao psiquismo a superação da dependência do sujeito ao objeto, permitindo a expansão de seus investimentos libidinais em direção a um campo vasto de objetos substitutos. É ela que possibilita a associação entre afetos e representações, assim como o contato com a realidade interna.

Para Farias e Cardoso (2010):

Este processo envolve um trabalho de luto, de elaboração da experiência de perda e representa, consequentemente, um processo de mudança no psiquismo, que deve reorganizar-se em função da assimilação das propriedades do objeto. . . . Ela 
contribui para o enriquecimento egoico, pois permite a apropriação das representações investidas, das quais os objetos primordiais são portadores; em outras palavras, permite a integração de elementos do mundo externo na esfera egoica e, além disso, uma metabolização dessa apropriação. (p. 143)

Podemos constatar, a partir das palavras das autoras, que a introjeção englobaria um trabalho de luto e elaboração da ausência materna e do narcisismo primário perdido, além de envolver um processo de mudança e reorganização, uma vez que são abertas novas possibilidades de representações psíquicas, o que, por sua vez, contribuirá para a constituição do sujeito.

Fernandes (2010) e Kalil (2010) defendem que a introjeção viria para substituir parcialmente a função da paraexcitação materna, dificultando que o aparelho psíquico do bebê fique à mercê da força pulsional. Dessa forma, a introjeção não é um mecanismo de compensação, mas de crescimento, ampliando e enriquecendo o ego, garantindo a constituição de um objeto interno que, na ausência da mãe, será capaz de assegurar as possibilidades de enfrentar as adversidades inerentes ao crescimento e aquisição da autonomia.

É pela introjeção que a criança adquire um conhecimento sobre seu corpo, sensações, necessidades e afetos. Do contrário, diante de uma falha na relação mãe-bebê, a introjeção pode não se realizar e o processo identificatório primário fica restrito à incorporação que instalaria 0 objeto perdido no interior de si, reforçando a dependência do sujeito.

Nos sujeitos com transtornos orais é possível observar que as ligações primárias não introduzem adequadamente a percepção das diferenças, prevalecendo a continuidade sensorial entre mãe e bebê. Assim, o sujeito não consegue tornar familiares características primordiais, que se manterão estranhas ao longo da sua vida. Brusset (1999) afirma que na bulimia, por exemplo, na falta dessa introjeção, o mecanismo de incorporação tende a ocupar a cena, reforçando a ligação com o objeto interno, que resultará na exigência constante da presença do objeto externo.

De acordo com Kalil (2010), o predomínio da incorporação, como defesa, reflete o desamparo do sujeito frente ao excesso pulsional. Ou seja, o sujeito que permanece desprotegido diante da perda do objeto, busca em objetos externos, tal como a comida, uma tentativa de tamponar a falta com a qual não consegue lidar, impossível de suportar, como um substituto dos objetos que lhe faltam, amenizando, provisoriamente, o desconforto e desamparo psíquico. A autora ressalta que o objeto-alimento passa a ser da ordem da demanda e não do desejo.

Observa-se que o sujeito não busca no alimento a satisfação da necessidade orgânica, mas abrandar angústias primitivas e evitar o aparecimento da falta. Assim, a obesidade mórbida e o comer compulsivo, especificamente, parecem ter um caráter autocalmante da ansiedade e da sensação de vazio. A relação com o excesso de comida teria como significado a reatualização da relação primitiva com a mãe, uma tentativa de recuperação do objeto amado que se perdeu.

Vale destacar que a incorporação é uma característica típica da relação objetal na fase oral, que mantém, como já discutido anteriormente, uma relação privilegiada com a atividade bucal e a ingestão de alimentos. Fernandes (2010) afirma que tanto a incorporação como a introjeção estão na base dos processos identificatórios, pois eles constituem os protótipos da identificação primária na relação pré-edípica entre mãe e bebê. Assim, não se resumem a meios de proteção, mas funcionam, também, como mecanismos constitutivos da subjetividade, que possibilitam a formação do limite corporal, a inclusão do sujeito na ordem da linguagem e da apropriação do sentido das palavras.

Com efeito, na falta de um investimento libidinal materno adequado, o sujeito não alcança a introjeção, vive seus conflitos no corpo, confunde o que é interno e externo, o registro do desejo com o da necessidade e, por isso, muitas vezes nesses casos, o analista é convocado a ocupar o lugar da mãe, de paraexcitação, quando se depara com a pulsão ainda em estado bruto, sem inscrição no psiquismo e, portanto, não representada.

Para Ansermet (2003), assim como o alcoolismo e a toxicomania, a anorexia e a bulimia seriam a saída patológica para um mesmo impasse, a descarga por meio do ato que pode ser compreendida como consequência de uma "desfusão" pulsional. Miranda (2010a) também ressalta os sintomas orais como defesas contra a "fusão" pulsional mãe-bebê e uma tentativa de individuação, uma vez que outras defesas fracassaram junto do processo de introjeção e simbolização.

Observa-se que as questões da autonomia e separação são elementos realçados por boa parte daqueles que trabalham com esta problemática. Os comportamentos dos sujeitos são descritos como uma tentativa de se livrar do sentimento de dependência, de apego e do medo de ficar fusionado ao objeto. Dessa forma, da impossibilidade de sentir o que se passa no nível do próprio corpo, da falta de simbolização e de uma integração do eu, resultaria o transtorno oral. $\mathrm{O}$ corpo estranho que invade a anoréxica e a bulímica é, ao mesmo tempo, o corpo do Outro, do qual elas querem se separar, e o corpo próprio, de que elas precisam se apossar.

Nesse contexto, Fernandes (2010) ressalta que o corpo estranho da anoréxica é um corpo recusado, em sua materialidade e necessidades, já o da bulímica se configura como hiperpresente e exigente. A autora afirma que, na anorexia, estamos diante da anestesia do corpo libidinal, de um não corpo, recusado em sua materialidade, necessidades e erogeneidade; enquanto na bulimia, poderíamos pensar em um autoerotismo negativo, devido à busca constante de sensações, e no desprazer frequentemente experimentado nesses atos. $\mathrm{O}$ ato bulímico submete o corpo aos excessos e à dor; existe aí um investimento libidinal que assegura a experiência do corpo. 
Observa-se, em todas essas saídas dos transtornos orais, uma falha na representação simbólica, pela negação do desejo e pela não acessibilidade ao objeto de satisfação, o que resulta na predominância da linguagem concreta, de acting-out. Miranda (2010a, 2010b) ressalta que, nesses casos, a boca se fecha para as palavras e se abre para o comer compulsivo e para os vômitos. Segundo a autora, o alimento e o se alimentar são representantes de grandes afetos e representam um desafio para as intervenções psicanalíticas, demandando complexidade de análise e a renúncia de relações lineares e reducionistas.

\section{Considerações finais}

Os sujeitos com transtornos alimentares estão cada vez mais presentes no cotidiano dos serviços de saúde mental, gerando demandas importantes, que exigem atenção especial daqueles que se propõem a acompanhá-los. Observamos taxas relevantes, gravidade clínica e níveis altos de complexidade que escancaram a necessidade de serviços especializados. A diversidade e a severidade dos sintomas, associados à ausência de intervenções preventivas e aos poucos serviços interdisciplinares especializados, geram demandas importantes no cotidiano dos serviços de saúde, o que acarreta na cronificação dos agravos.

Apesar de serem transtornos que afetam eminentemente o corpo, com sintomas físicos e clínicos que são dirigidos privilegiadamente ao médico, tratam-se de um intenso sofrimento psíquico, questões subjetivas que precisam ser consideradas. Atualmente há um consenso sobre as limitações disciplinares na apreensão dos objetos a serem investigados e a importância da interlocução entre as diferentes áreas. O trabalho integrado é ressaltado como uma das respostas ao desafio da interlocução, uma vez que possibilitará o surgimento de duas dimensões distintas, mas que estão diretamente interligadas: uma relativa à construção do conhecimento e outra que se refere à ação interventiva. Ainda que não haja no plano teórico uma articulação efetiva, o trabalho integrado deve ultrapassar o diálogo sobre e entre os saberes e práticas, gerando novos conhecimentos e ações com chances mais efetivas de apreensão do fenômeno e de intervenção terapêutica.

Na clínica dos transtornos da alimentares, a participação da nutricionista se destaca no ensino à ingestão dos alimentos e no balanceamento adequado de valores calóricos considerados normais a serem ingeridos, assim como a suplementação de vitaminas necessárias para o bom funcionamento do organismo. Porém todo esse trabalho não teria a mesma efetividade sem a participação da psiquiatria que com a medicação consegue ter maior controle sob as condições emocionais que acompanham o paciente como a ansiedade e a depressão.

Destacamos aqui a participação fundamental destes profissionais durante todo o processo, mas evidenciamos que junto das questões físicas e comportamentais, não é difícil observamos sujeitos com intensa dificuldade de comunicação consigo e com o mundo a sua volta. Por não encontrarem outra forma de expressão verbal, os sintomas corporais falam pelo sujeito (come, engorda, vomita, purga, jejua). Seus comportamentos alimentares provocam angústias que lhe concedem um lugar no mundo, que, de outra forma, possivelmente, não saberia ocupar. Será pelo excesso ou pela falta que o sujeito se faz visível.

A partir de uma leitura psicanalítica, evidenciamos a importância do investimento libidinal da mãe sobre o bebê, garantindo não só a sobrevivência da criança através de objetos que supram as necessidades vitais, mas também lhe oferecendo amor e suporte simbólico para possibilitar sua assunção subjetiva. Nesse contexto, observamos ainda a importância da figura paterna como representante máximo de interdição dessa relação mãe-bebê e como fator estruturante para o sujeito mediante a triangulação edípica.

Os sintomas orais dessas jovens evidenciariam a falha da constituição psíquica do sujeito, sobretudo, das relações primárias e seus desdobramentos. Eles também parecem se manifestar como meios encontrados para fazer borda ao corpo, lidar com as demandas pubertárias e reafirmar seu desejo perante a onipotência materna em uma tentativa de adquirir identidade.

Essas questões subjetivas que se apresentam nos prontuários corroboram com a ideia sobre os limites da leitura biomédica e com os possíveis entraves que sua hegemonia na condução dos atendimentos pode acarretar. Nesse sentido, deparamos com a problemática de inserir a psicanálise no trabalho integrado e suas questões subjetivas nas discussões da equipe e no trabalho individual de cada profissional. Mais do que uma problemática, é um desafio pensar para o campo da saúde mental que, para perspectivas tão distintas, seja possível um trabalho em comum.

Nesse contexto, é fundamental que a dinâmica entre vários profissionais aconteça em um solo comum para a sustentação do plano terapêutico, do contrário, torna-se impossível à equipe avançar em suas questões. Os sujeitos com transtornos alimentares estabelecem situações de risco real de morte, o que torna necessário o trabalho organizado em equipe para o seu acompanhamento.

\section{The oral disorders biomedical perspective and its ramifications in psychological services}

Abstract: This article aims to analyze the ramifications of the biomedical perspective in psychological services on an interdisciplinary service of nutritious disorders. The methodology consists of a documental research of medical registers of patients attended on the program who were diagnosed with nutritious disorder and that were being attended on the period between August 2012 and January 2013. The clinical categories privileged on this analysis were transference, symptoms and diagnosis. There was a total of 17 medical registers, all of female gender, aging between 14 and 61 years. Besides the 
prevalence of the biomedical discourse on the sessions report we identified subjective questions present on the patients discourse, but they were not extensively elaborated, such as familiar relationships, orality questions, puberty and femininity. From the psychoanalytical theory of Freud and Lacan, we discuss the mentioned questions, pointing out the importance to the comprehension and following of patients with nutritious disorders.

Keywords: biomedicine, psychoanalysis, interdisciplinary clinic, nutritious disorder.

\section{La perspective biomédicale des troubles alimentaires et son développement dans l'assistance psychologique}

Résumé: Cet article a pour but analyser le développement de la perspective biomédicale dans l'assistance psychologique sur un service interdisciplinaire de troubles alimentaires. La méthodologie repose sur une enquête documentaire de dossiers des patients traités dans le programme et diagnostiqués avec trouble alimentaire, ils ont été traités pendant la période d'Août 2012 à Janvier 2013. Les catégories cliniques envisagées dans cette analyse sont transfert, symptômes et diagnostic. En tout, ce sont 17 dossiers de patients, tous du sexe féminin, de 14 à 61 ans. Nous avons identifié au-delà de la prévalence du discours biomédical dans les comptes rendus des sessions, questions subjectives présentes dans le discours du patient, mais peu élaborées dans les dossiers, telles que les relations familiales, les questions de l'oralité, puberté et de la féminité. À partir de la théorie de Freud et Lacan, nous avons discuté ces questions, en soulignant l'importance pour la compréhension et le suivi des patients avec troubles alimentaires.

Mots-clés: biomédecine, psychanalyse, clinique interdisciplinaire, trouble alimentaire.

\section{La perspectiva biomédica de los transtornos alimentares y suyos desdoblamientos en atendimientos psicológicos}

Resumen: Este artículo tiene como objetivo analizar los desdoblamientos de la perspectiva biomédica en atendimientos psicológicos en un servicio interdisciplinar de transtornos orales. La metodología consistió in una investigación documental de prontuarios de los pacientes atendidos en el programa diagnosticados con transtorno alimentar y que estaban en atendimiento en el período de Agosto de 2012 a Enero de 2013. Las categorías clínicas privilegiadas en este análisis fueran transferencia, síntomas y diagnostico. Al todo fueran 17 prontuarios, todos de pacientes del sexo femenino, con edades entre 14 y 61 años. Identificamos allá de la prevalencia del discurso biomédico en los relatos de sesiones, cuestiones subjetivas presentes en el discurso del paciente, más poco elaboradas en los prontuatrios, como las relaciones familiares, cuestiones de la oralidad, pubertad y da feminidad. Partiendo de la teoría psicoanalítica de Freud y Lacan, discutimos tales cuestiones, resaltando la importancia para la comprensión y acompañamiento de pacientes con transtornos alimentares.

Palabras clave: biomedicina, psicoanálisis, clínica interdisciplinaria, transtornos alimentares.

\section{Referências}

Ansermet, F. (2003). A recusa anoréxica. In F. Ansermet, Clínica da origem: a criança entre a medicina e a psicanálise. Rio de Janeiro, RJ: Contra Capa.

Bosi, M. L. M., \& Andrade, A. (2004). Transtornos do comportamento alimentar: um problema de saúde coletiva. Cadernos de saúde coletiva, 12(2), 197-202.

Brusset, B. (1999). Conclusões terapêuticas sobre a bulimia. In R. Urribarri (Org.), Anorexia e bulimia. São Paulo, SP: Escuta.

Camargo Jr., K. R. (1997). A biomedicina. Physis: Revista de Saúde Coletiva, 7(1), 45-68.

Cicco, M. F. (2010). Transtornos alimentares e a função do analista na clínica do não-representado. In A. P. Gonzaga, \& C. Weinberg (Orgs.), Psicanálise de transtornos alimentares. São Paulo, SP: Primavera.
Conselho Federal de Psicologia (2009). Resolução CFP n ${ }^{\circ}$ 001/2009. Dispõe sobre a obrigatoriedade do registro documental decorrente da prestação de serviços psicológicos. Recuperado de http://site.cfp.org.br/wpcontent/uploads/2009/04/resolucao2009_01.pdf

DSM-IV (1995). Manual diagnóstico e estatístico de transtornos mentais. Porto Alegre, RS: Artes Médicas.

Farias, C. P., \& Cardoso M. R. (2010). Incorporação e expulsão do "outro" na bulimia. In A. P. Gonzaga, \& C. Weinberg (Orgs.), Psicanálise de transtornos alimentares. São Paulo, SP: Primavera.

Fernandes, M. H. (2010) O corpo recusado da anorexia e o corpo estranho na bulimia. In A. P. Gonzaga, \& C. Weinberg (Orgs.), Psicanálise de transtornos alimentares. São Paulo, SP: Primavera. 
Freire, D. S., \& Andrada, B. C. (2012). A violência do/no corpo excessivo dos transtornos alimentares. Cadernos de Psicanálise, 34(26), 27-36.

Freud, S. (1996a) Sobre a psicanálise. Edição Standard brasileira das obras psicológicas completas de Freud. Rio de Janeiro, RJ: Imago. (Trabalho original publicado em 1913).

Freud, S. (1996b) Uma nota sobre o inconsciente na psicanálise. Edição Standard brasileira das obras psicológicas completas de Freud. Rio de Janeiro, RJ: Imago. (Trabalhos original publicado em 1912).

Gorgatti, S. B. (2002). O feminino congelado na anorexia. In S. L. Alonso, (Org.), Figuras clínicas do feminino no mal-estar contemporâneo. São Paulo, SP: Escuta.

Jeammet, P. (1999). A abordagem psicanalítica dos transtornos das condutas alimentares. In R. Urribarri (Org.), Anorexia e bulimia. São Paulo, SP: Escuta.

Kalil, F. (2010). A compulsão alimentar e suas implicações na clínica psicanalítica. In A. P. Gonzaga, \& C. Weinberg (Orgs.), Psicanálise de transtornos alimentares. São Paulo, SP: Primavera.

Lacan, J. (1998a). A direção do tratamento e os princípios de seu poder. In J. Lacan, Escritos. Rio de Janeiro, RJ: Zahar. (Trabalho original publicado em 1958).

Miranda, M. R. (2010a). A complexidade da relação mãe-filha nas patologias dos contrários. In C. A. N. Bruno, Distúrbios alimentares: uma contribuição da psicanálise. São Paulo, SP: Imago.
Miranda, M. R. (2010b). A representação simbólica nas perturbações alimentares à luz da complexidade mãefilha. In A. P. Gonzaga, \& C. Weinberg (Orgs.), Psicanálise de transtornos alimentares. São Paulo, SP: Primavera.

Nazar, T. P. (2013). Você tem fome de quê? Três abordagens dos transtornos da alimentação. Rio de Janeiro, SP: Cia de Freud.

Organização Mundial de Saúde (1993). Classificação de transtornos mentais e de comportamento: CID-10. Porto Alegre, RS: Artes Médicas.

Priore, M. D. (2006). Prefácio. In C. Weinberg, \& T. A. Cordás (Orgs.), Do altar às passarelas: da anorexia santa à anorexia nervosa. São Paulo, SP: Annablume.

Sousa, P. R. (1991). Os sentidos do sintoma: psicanálise ou gastroentereologia (Tese de doutorado). Faculdade de Ciências Médicas, Universidade Estadual de Campinas, São Paulo.

Zanetti, S. A. S., \& Kupfer, M. C. M. (2006). O relato de casos clínicos em psicanálise: um estudo comparativo. Estilos da clínica, 11(21), 170-185.
Recebido: 24/04/2014

Revisado: 06/12/2014

Aceito: 16/12/2014 